\title{
A consolidação institucional do cargo de dirigente público
}

\section{Introdução}

Este trabalho pretende desenvolver uma reflexão sobre a profissionalização dos cargos de direção na administração pública e sua evolução ao longo das últimas décadas nos países desenvolvidos, tendo como eixo condutor a institucionalização dos cargos de dirigentes públicos nos sistemas político-administrativos contemporâneos.

O texto será estruturado da seguinte forma: iniciará definindo a expansão e o desenvolvimento do gerenciamento nos sistemas públicos, descrevendo, de forma breve e comparada, sua evolução mais recente em alguns países da Organização para Cooperação e Desenvolvimento Econômico (OCDE). Em seguida, serão apontados os traços básicos de um modelo de exercício das funções de direção na administração pública. A seguir, será abordado o tema central mencionado. Para isso, serão definidos, primeiramente, os elementos que configuram um marco institucional para as funções de direção no setor público. Em segundo lugar, serão abordados o conteúdo, o alcance e o âmbito das reformas necessárias para a construção desse marco. Por último, serão analisadas as variáveis que podem influenciar a elaboração das reformas, expondo-se os principais desafios e dificuldades traçados pelos empenhos de reforma.

\section{O surgimento da gerência pública}

Nos sistemas públicos em que se encontram - como ocorre nas democracias avançadas - os elementos básicos constitutivos de uma

Francisco

Longo é

licenciado em Direito pela

Universidade

de Barcelona, professor e diretor do Instituto de Dirección y Gestión Pública da ESADE em Barcelona, Espanha.

Contato: longo@esade.edu 
administração profissionalizada, a ação pública tem sido conduzida, durante décadas, com os devidos ajustes ao conhecido modelo weberiano, por dois grandes protagonistas: a classe política, investida de autoridade mediante mecanismos da democracia representativa, e a burocracia profissional, regida pelo sistema de mérito.

O surgimento dos dirigentes públicos supõe a ruptura desse dualismo, profundamente interiorizado, ao longo do tempo, não só no funcionamento da administração, mas também na própria consciência social. Que causas produzem a crise desse modelo? A que se deve o surgimento da reforma gerencial?

As bases profundas da crise do paradigma weberiano apareceram há décadas, tão logo iniciada a evolução dos Estados modernos em direção ao que hoje chamamos de Estado provedor, social ou de bem-estar. Pensando no contexto do Estado liberal, como garantia da aplicação imparcial e impessoal da norma, a burocracia weberiana manifesta precocemente, ao menos no plano da análise, sua não-adaptação a essa evolução. A crescente tomada de responsabilidade dos governos pela provisão de serviços públicos, em sua maior parte sob a modalidade de prestação direta, incorpora gradualmente a dimensão empresarial em boa parte da atuação pública. A legitimidade governamental, originariamente subordinada ao direito, deve ser complementada com a legitimidade pela eficácia.

A enorme expansão da capacidade de prestação de serviços do setor público dá lugar a uma crescente complexidade e diversificação dos processos de produção dos serviços (Echebarria, 1993, p. 93 et seq.). A necessidade de haver atores capazes de estar à frente desses processos, garantindo sua eficácia, não foi adequadamente satisfeita por nenhum dos principais atores do sistema. O cenário era adequado para a ruptura desse dualismo, contudo isso não ocorreu até recentemente, quando o fenômeno gerencial se impôs na prática, em muitos casos, ou quando foi assumido como tendência desejável, em muitos outros (Cabrero, 1991).

A explicação mais consistente e ampla da análise desse processo é um tanto quanto paradoxal. Se por um lado, ao nascimento e desenvolvimento do Estado de bem-estar incorporavam-se as necessidades apontadas anteriormente, por outro, será precisamente a sua crise que fará aflorar e difundir as respostas a esse dualismo. A crise fiscal e a crescente restrição de recursos à disposição dos governos atuarão como forças impulsionadoras capazes de questionar o status quo e implantar um modelo alternativo.

Para Sue Richards (1994, p. 5-9), que analisa o fenômeno a partir da experiência britânica, com explicações aplicáveis à nossa realidade, a fase de expansão do Estado de bem-estar foi protagonizada principalmente por dois atores: os políticos e os profissionais burocratas (técnicos e especialistas incorporados à administração para prestação de volume 
crescente de serviços). Ambos operavam como forças que ampliavam o escopo das respostas do setor público. Os primeiros, pressionados por demanda social crescente cuja satisfação era a chave para competir com êxito no mercado eleitoral. Os segundos, impulsionados por essas mesmas necessidades, vividas em sua relação com os usuários reais ou potenciais dos serviços, assim como pelo seu interesse em consolidar sua importância no sistema. Entre os dois, uma burocracia débil, administrando e dando forma às intervenções e transações dos principais atores.

O modelo pode subsistir, segundo a autora britânica, enquanto for possível nutrir suas intrínsecas tendências expansivas mediante o incremento dos orçamentos públicos. Quando a magnitude alcançada pelo gasto público e a necessidade de políticas orçamentárias restritivas questionam a viabilidade econômica desse modelo, os políticos precisam introduzir disciplina no sistema. A incorporação dos managers, ou dirigentes públicos, portadores dos valores e saberes próprios da racionalidade econômica, permite aos políticos orientar a administração em direção à produção de melhorias de eficiência.

Duas notas são significativas nesta análise. A primeira é que o fenômeno gerencial aparece vinculado a uma reação das classes políticas dirigentes, destinadas a controlar o sistema, impondo seu poder sobre o que Clarke e Newman (1997, p. 13) chamam de coalizão buro-profissional, utilizando para isso novo ator, o dirigente, que assumirá papel de destaque. A segunda é que a função de direção, ainda que necessária, e sendo conseqüência da lógica evolutiva do Estado moderno, não se desenvolve senão impulsionada pela crise de recursos e restrição de gastos públicos. Essa segunda nota explica o foco na eficiência - com forte orientação à redução de gastos -, que foi amplamente adotado com o surgimento dos managers e gerou algumas das conseqüências mais discutíveis desses processos.

Em nossa estrutura pública, o fenômeno gerencial é, sem dúvida, muito mais incipiente do que no Reino Unido ou em outros países que têm vivido processos de ampla transformação de seus sistemas públicos, como Austrália, Nova Zelândia, Suécia ou Dinamarca (Schwartz, 1994; Boston et al., 1997). Mais incipiente também do que muitos outros (Estados Unidos, Canadá, Holanda), em cujas tradições administrativas a função de direção tem alcançado grau notável de desenvolvimento. Países de cultura administrativa mais próxima à nossa, como a Itália, têm impulsionado reformas destinadas a consolidar a chamada dirigenza pubblica como extrato dotado de lógica e característica próprias e diferenciadas da função pública comum.

Caso sustentemos, no entanto - e creio que devemos fazê-lo -, que a análise anterior resulta da simples aplicação à administração pública de nossos países e também que o formato dual (políticos/burocratas) é 
um modelo insuficiente e perigoso, encontraremos, na maior parte dos casos, espaço por preencher, o que corresponderia ao exercício da função de dirigente público.

Do ponto de vista da análise organizacional, a existência de espaço vazio ou semivazio é uma situação mais teórica do que real. Como se estivessem afetadas de horror vacui, as organizações costumam produzir tendência interna a ocupar qualquer brecha que apareça na sua estrutura, sob o duplo impulso de atender às necessidades criadas e de satisfazer as expectativas de poder de seus atores internos. O espaço dos cargos de direção é disputado, com resultados variáveis e diferentes nas diversas instituições, por dois atores tradicionais dos sistemas públicos: a classe política e a burocracia profissional. Em outro texto, argumentamos por que, nenhum deles pode responder satisfatoriamente aos desafios apontados (Longo, 1999).

\section{O desenvolvimento da funcão de direção}

Não há management sem managers. As reformas que, sob diferentes lemas e denominações, com clara diferença de ambição e profundidade, mas com uma consistente coincidência de conteúdo (Barzelay, 1998, 2001. Clarke; Newman, 1997. Dunleavy; Hood, 1994. Metcalfe, 1993. Pollitt, 1993. Pollitt; Bouckaert, 2000. OCDE, 2000), vêm se desenvolvendo nos sistemas político-administrativos de boa parte do mundo exigem a figura do dirigente. A mais contundente das orientações à eficiência e à racionalidade econômica e os melhores instrumentos e técnicas de gestão estariam propensos a fracassar se não houvesse os dirigentes (Dalziel, 1996, p. 31).

O problema é que os sistemas tradicionais de serviço público carecem, em geral, de capacidade para produzir perfis de dirigentes na proporção requerida pelas reformas e tampouco dispõem de mecanismos capazes de estimular devidamente a prática gerencial. Por isso, a profissionalização dos quadros de direção converteu-se em prioridade para os reformistas (Murray, 2000, p. 180), obrigando-os a concentrar políticas específicas de gestão de recursos humanos na camada superior dos sistemas de serviço público (Losada, 1999).

Com certa freqüência, como veremos em seguida, esse objetivo tem exigido diferenciar a função de dirigente das outras funções no setor público e dotá-la de estatuto específico e mais flexível do que o aplicável aos demais servidores. Certamente, existem países, como França, Alemanha, Bélgica e Espanha, que não aderiram a essa tendência. Isso impediu o uso crescente do desenvolvimento de dirigentes nesses países, 
onde o desenvolvimento da gerência pública ainda apresenta déficit significativo de institucionalização (Jiménez Asensio, 1995).

A distinção a que nos referimos não deve ser confundida com a absoluta discricionariedade na nomeação de dirigentes por critérios políticos (Longo, 1999). Os governos necessitam de certo número de nomeações políticas, que costumam acontecer mediante certas técnicas. Assim, na França, por exemplo, são basicamente orçamentárias as limitações ao quantitativo de pessoal sob nomeação direta dos ministros. Atualmente, isso corresponde a aproximadamente 450 cargos (Burnham, 2000, p. 101). Nos EUA, cerca de $10 \%$ do serviço superior mais alguns cargos específicos da executive schedule somam cerca de 1.350 cargos do quadro executivo federal. Na Suécia, o número desses cargos é fixado por acordos entre os partidos. Na Alemanha e Bélgica, existem sistemas híbridos de nomeação para esses cargos, utilizando-se do sistema de pool. Para formar parte desse pool, consideram-se certos requisitos, como formação universitária e ocasionalmente aprovação em uma prova, mas seus integrantes podem ser objeto de nomeação política e discricionária (World Bank, 2000).

A orientação diferenciada a que fazíamos referência fundamentase em modelos de separação entre política e gestão (Jiménez Asensio, 1998), que partem do reconhecimento de esfera gerencial a ser preenchida por dirigentes públicos subordinados ao mandato político, mas a quem se reconhece esfera própria de decisão exercida sob marcos contratuais (Laegreid, 2000), baseados no princípio de responsabilização por resultados. Algumas das reformas que afetaram os cargos superiores do serviço público tiveram essa orientação.

Assim, no Reino Unido (OCDE, 1999, p. 8), criou-se, em 1996, o Senior Civil Service (SCS), que englobava e ampliava a antiga Open Structure do SC (Serviço Civil), incorporando os 3.000 cargos dos escalões superiores da administração britânica. O SCS inclui todos os diretores executivos das agências, alguns dos quais são recrutados fora do serviço público, por meio de contratos de duração limitada e renovável. A maioria, contudo, tem contratos de duração indefinida. Os cargos do SCS são avaliados mediante novo sistema de valoração de cargos (Job Evaluation for Senior Posts), concomitante com formas de remuneração variável por desempenho. A política salarial depende de um departamento que se reporta diretamente ao primeiro-ministro. Sistemas avançados de gestão do desempenho, incluindo avaliações de 360 graus e outras técnicas, foram implantados no SCS pelo Cabinet Office.

Nos Estados Unidos (OCDE, 1999, p. 21), o Senior Executive Service (SES) foi criado em 1978 pela Lei de Reforma do Serviço Civil. Compreende cerca de 7.000 cargos (número demasiado, segundo alguns 
especialistas, para poderem ser qualificados como elite), entre os quais se encontram os $10 \%$ que, como antes se disse, podem destinar-se a nomeações políticas, embora (Ingraham et al., 1995) não tenham ainda superado os $9 \%$. Certamente, a análise das diferenças no comportamento dos dirigentes de uma e outra procedência não apresenta nuâncias muito significativas (Dolan, 2000). Os efeitos combinados dos cortes orçamentários, o downsizing e as reformas dos últimos anos têm afetado o SES de diversas formas. As reformas mais recentes, com a criação das Performance Based Organisations (PBOs), são inspiradas nas agências britânicas, introduzindo novos patamares de desempenho para os dirigentes.

Na Austrália, o SES foi criado pela Lei de Reforma do Setor Público de 1984, no contexto de uma reforma que tinha como prioridades (Pollitt; Bouckaert, 2000, p. 202) reduzir a permanência dos servidores públicos, diversificar as fontes de assessoramento político aos ministros e incrementar tanto a capacidade gerencial como a receptividade dos servidores públicos, de acordo com as prioridades políticas do governo.

Na Itália, a criação, pela reforma de 1993, da Dirigenza Pubblica (Sánchez Morón, 1994. Martínez Bargueño, 1995, p. 34) teve como fundamento o alcance de distinção nítida entre os planos de direção política e administrativa, com o objetivo de reforçar a autonomia dos dirigentes públicos quanto ao poder político e garantir-lhes âmbito próprio de atuação, livre de interferências, ainda que condicionado pelos objetivos políticos. Uma das características da reforma italiana é sua vontade de estender o modelo a todas as esferas da administração pública. Em função da posição hierárquica e da maior ou menor flexibilidade do sistema de nomeação, o modelo italiano faz distinção entre os níveis de dirigente geral (nomeação mediante verificação de requisitos) e dirigente (nomeação mediante aprovação em prova ou curso de capacitação).

Na Holanda, a reforma de 1995 criou, depois de muitos anos de debate (Van der Krogt et al., 2000, p. 197), o Alto Serviço Público (ABD), que compreende os 300 cargos mais altos do governo central, prevendo a ampliação desse número. Os objetivos da criação do ABD foram: o desenvolvimento das habilidades de direção, a promoção da mobilidade e da experiência internacional e o desenvolvimento de um esprit de corps. Existem estímulos à rotatividade e restrições à permanência em um mesmo cargo por mais de sete anos. Um departamento especial do ABD no Ministério do Interior recruta e seleciona pessoas e desenvolve elaborado programa de formação e avaliação.

No caso canadense (OCDE, 1999), a alta administração tem sido tradicionalmente um grupo de elite caracterizado por ser recrutado em universidades de prestígio, bem como por ter um sistema centralizado de pessoal e emprego vitalícios. A situação (“modelo Westminster") é similar à do Reino Unido no início das reformas da década de 80. A incontestável 
mudança de estrutura não tem dado lugar, no Canadá, a uma reforma profunda, já que os governos parecem estar mais interessados em políticas de economia e redução de pessoal do que em transformações globais.

Uma das características gerais dos novos modelos de cargos de direção profissionalizados é a abertura dos postos, em muitos casos, fora da administração, combinando o acesso de executivos procedentes do setor privado com o recrutamento - majoritário - de pessoas provenientes do serviço público.

\section{Modelo para o exercício da função de direção}

A busca de modelo que sirva de referência para a prática da direção é sempre uma tarefa difícil, mas a dificuldade é ainda maior no contexto da administração pública. A função de direção ainda está pouco arraigada no repertório de modelos e convicções interiorizadas pelas organizações e sistemas públicos, o que torna obscuros os contornos da própria noção de gerência pública e a faz suscetível de estimativas e formulações diferentes.

É justamente esse caráter ainda impreciso da situação que está fazendo com que a função de direção torne-se vulnerável aos perigos externos que, às vezes, distanciam-se da sua razão de ser. Em particular, são evidentes os perigos de apropriação da função de dirigente pelos atores tradicionais antes mencionados (Longo, 1999). Assim ocorre quando a administração pública se politiza e assume caráter clientelista, colonizador do espaço de direção pelas classes políticas e pelos interesses partidários. Esse também é o caso quando as funções de direção se burocratizam e se convertem em mera execução de normas ou aplicação de procedimentos e pautas definidas por inércia, bem como se distanciam da responsabilização pelos resultados, como ocorre quando a burocracia comum se apossa dessa direção e a desnaturaliza.

Não defendemos, de imediato, a existência de modelo de referência único e excludente para o exercício das funções de direção no setor público. No entanto, parece-nos desfrutar merecidamente de amplo conhecimento e grande aceitação a idéia proposta pela Kennedy School of Government (KSG) da Universidade de Harvard, exposta, entre outros, por Mark Moore (1995), que considera o dirigente como "criador de valor público". Para o autor norte-americano, essa criação de valor implica atuação em três esferas interrelacionadas.

A primeira - a gestão estratégica - supõe que o dirigente reflita estrategicamente e produza idéias sobre como a organização, qualquer 
que seja sua escala, pode criar o máximo valor; considera, se for o caso, alterar os pressupostos sobre os quais vêm atuando, reformular a missão e inovar quando as circunstâncias forem necessárias.

Para desenvolver essa estratégia, o dirigente precisa operar na segunda esfera - Moore a chama de political management, que traduziremos, não sem ressalvas, como gestão do entorno político - com o objetivo de obter a legitimidade, as autorizações, o apoio, a colaboração e os recursos necessários, administrando suas relações com um grupo de atores, internos e externos, que constituem seu "entorno autorizante". Esse entorno inclui, acima de tudo, os seus superiores políticos, mas também todos aqueles atores sobre os quais ele não tem autoridade formal: outros dirigentes da própria organização ou de outras, grupos de interesse, cidadãos, meios de comunicação, etc.

Por último, trabalhando na terceira esfera - a gestão operacional -, o dirigente deve buscar que a organização a qual dirige, composta pelo conjunto de meios e recursos sob sua autoridade formal, atue eficaz e eficientemente para alcançar os objetivos delineados e, além disso, deve assumir a responsabilidade pelos resultados alcançados.

Este último seria o terreno mais conhecido e convencionalmente aceito para o exercício da direção. No entanto, a função de dirigente ficaria, como afirma Moore, empobrecida, se nos limitássemos a ele, ignorando as esferas da gestão estratégica e política. Isso suporia pedir a dirigente público menos do que nossas sociedades estão acostumadas a exigir de dirigente privado, de executivo de uma empresa. Provavelmente, a complexidade dos problemas enfrentados pelo setor público e a obscuridade de seus "entornos autorizantes" tornam essas esferas de gestão mais exigentes no âmbito público do que no privado. Bourgault e Savoie (2000, p. 376), em recente trabalho sobre a alta administração canadense, ressaltam essa dimensão da função gerencial pública de forma coincidente com a do modelo descrito.

A adoção do modelo da KSG como referência é compatível com uma visão imprecisa do trabalho do dirigente. O êxito ou fracasso do dirigente implica necessidades que operam de maneira distinta em diferentes contextos, como manifesta a tipologia de perfis dos dirigentes de Strand (1987), útil como marco analítico para reconhecer diversos graus e formas de manifestação da liderança na gerência pública. Partindo de duas dimensões, o grau de estabilidade/mudança, de um lado, e a orientação com preferência a regularidade/resultados, de outro, apresentam tipologia de dirigentes públicos formada por quatro arquétipos: o administrador, o produtor, o empreendedor e o integrador. Cada um deles poderia ser visto como concretização distinta do dirigente genérico de Moore, em circunstâncias específicas e diferentes. 
Essa discussão sobre a função de direção no setor público, sem dúvida rigorosa, é coerente com a que se depreende dos trabalhos mais recentes do Comitê de Gestão do Serviço Civil do Reino Unido (Civil Service Management Board - CSMB), destinados à produção de modelo de competências de direção para o HSCS. Os "valores" e "temas" que configuram o modelo básico de direção no setor público para o CSMB incluem elementos como inovação, criatividade, aprendizagem, visão aberta ao exterior, trabalho em alianças ou redes, juntamente com outros mais próprios à gestão operacional.

\section{Marco institucional para a função de direção no setor público}

Que ajustes institucionais possibilitam a existência da função de direção no setor público, sob o alcance que se depreende das reflexões anteriores? Quais são os principais elementos configuradores de ecossistema institucional capaz de viabilizar o pleno desenvolvimento e a consolidação da gerência profissionalizada nos governos e organizações do setor público? Propõe-se uma tentativa de resposta a essas perguntas, com o propósito de lançar idéias e prover elementos para o debate e a reflexão, sem a pretensão de chegar a conclusões definitivas. Assim, entende-se que as regras do jogo, formais e informais, necessárias para que a gerência profissionalizada frutifique nos sistemas públicos devem garantir, acima de tudo, a existência de marco de responsabilidade de direção integrado por quatro elementos básicos, que serão trabalhados adiante ${ }^{1}$.

\section{Âmbito de discricionariedade}

Não existe exercício de direção sem a capacidade para colocar opções em prática e tomar decisões. Não há gerência onde a atividade é, fundamentalmente, mera aplicação de normas ou execução de instruções originárias de outros. Quando o que se espera do servidor público é a aplicação impessoal de regras e a observância fiel de procedimentos preestabelecidos, como acontece no modelo burocrático clássico, a atribuição de autoridade hierárquica não equivale à habilitação real para o exercício de função de dirigente, da forma que é concebida no setor privado.

Por isso, os reformistas britânicos dos anos de 1980 imprimiram a expressão right to manage para aludir à necessária ampliação da discricionariedade de direção exigida por seu propósito de "gerencializar" os serviços públicos. A própria pretensão de tornar os executivos públicos responsáveis perante o poder político levava consigo a necessidade de ampliar o grau de autonomia para tomada de decisão. Só assim caberia 
introduzir mecanismos de prestação de contas sobre os resultados da gestão, indo mais além dos controles procedimentais típicos das burocracias, incapazes de assegurar a eficácia e eficiência nos processos de produção dos serviços.

Para a construção desse âmbito de discricionariedade de direção, torna-se imprescindível transformar as relações dos dirigentes com duas instâncias de poder diferentes dentro das organizações públicas, respeitando as características das burocracias tradicionais. Essas instâncias são os políticos de governo, de um lado, e os tecnocratas, de outro.

No que diz respeito aos primeiros, a ampliação da autonomia de direção se produz na forma de delegação formalizada, institucionalizada, e não secundária ou meramente voluntária. Pode-se compreender o alcance dessa delegação, se se caracterizá-la como renúncia estável à interferência política na esfera das decisões próprias da gestão. A decisão política reserva-se preferencialmente à formulação de prioridades e linhas de atuação estratégica e à distribuição dos recursos, enquanto a gerência assume a responsabilidade de dirigir os processos que permitem a implementação das políticas e a produção e provisão dos serviços públicos. Não é necessário dizer que a distribuição entre ambos os campos é imprecisa e que a dificuldade em delimitá-los oscila dependendo de diferentes variáveis, que ocorrem, por sua vez, de modo heterogêneo nas diferentes áreas de ação pública. Os desenhos institucionais desenvolvidos pela administração pública basearam-se neste novo marco relacional entre políticos e dirigentes, a partir de base contratual (o formato principalagente) que, mais ou menos formalizada, tentou explicitar dentro do possível, em cada caso, as novas regras do jogo. Os contratos ou acordos de gestão, ou public service bargains (Hood, 2000), caracterizaram boa parte das reformas em diferentes países.

A segunda instância afetada por essa ampliação da atuação do dirigente é constituída pelas tecnoestruturas, isto é, segundo Mintzberg (1984, p. 56), os órgãos que assumem dentro das organizações as responsabilidades de normalizar, padronizar, planejar e controlar a atuação das instâncias de base ou diretamente produtivas. Incluem-se aqui os interventores, diretores das áreas de orçamento e de pessoal, auditores, gestores ou supervisores de abastecimentos, gerentes de organização e métodos, etc. A capacidade de dirigir é inseparável da possibilidade de tomar certas decisões sobre áreas como a financeira ou de recursos humanos, o que entra em choque com as práticas habitualmente centralizadas das burocracias públicas. Conseqüentemente, a transformação do marco relacional produz-se, aqui, com a transferência aos gestores de poderes anteriormente exclusivos aos órgãos técnicos. Estes, por sua vez, enfrentam mudança substancial no seu papel dentro das organizações, como conseqüência das transformações nos sistemas de controle, aos quais faremos alusão em seguida. 
A abertura do espaço que possibilita margem de discricionariedade

própria da gerência requer desenho institucional descentralizado (Pollitt; Birchall; Putnam, 1998). Se não se encontrar esse tipo de estrutura, ou se a descentralização for insuficiente, ambígua, oscilante ou meramente retórica, estará em questão, inevitavelmente, um elemento fundamental do marco de responsabilidade próprio dos dirigentes públicos.

\section{Sistema de controle e prestação de contas}

Falar de marco de responsabilidade gerencial implica a existência de mecanismos formais de controle do desempenho do dirigente. Tais mecanismos podem ser vistos como contraponto necessário à existência de estrutura descentralizada, na qual o dirigente opera com margem significativa de poder de decisão, conforme foi apontado. Esse contraponto constitui a base do contrato de gestão, mais ou menos formalizado, referido anteriormente.

Os controles próprios das funções de direção, coerentes com a existência do âmbito de discricionariedade referido, são preferencialmente os que operam sobre os resultados de atuação gerencial. Como descreve a teoria da organização, os sistemas de planejamento e controle de resultados - com a diferença dos que normatizam e controlam ações ou procedimentos - estão presentes basicamente no princípio e final do ciclo de gestão, isto é, nos momentos de definição de metas e distribuição de recursos e nos momentos de avaliação de resultados (Longo, 1999, p. 220). Nos estágios intermediários do ciclo, há controles hands off, que tomam a forma de acompanhamento com desejo de não intervir, salvo em casos excepcionais, que ficam reservados a hipóteses de desvios muito significativos dos padrões de resultados ou de procedimentos estabelecidos. Somente assim, os controles serão compatíveis com a prestação de contas e a exigência de responsabilidade pelos resultados.

O controle do desempenho forma parte dos musts da gestão pública contemporânea. No entanto, às vezes é mais fácil encontrá-lo nos textos que nas práticas organizacionais. Sua incorporação no dia-a-dia da administração enfrenta diversos tipos de dificuldades. Os especialistas já destacaram (Mendoza, 1993, p. 44 et seq.) como a implantação desse controle de desempenho enfrenta, além dos obstáculos técnicos, as resistências de profunda mudança cultural, que deve ser adequadamente administrada.

O que importa destacar neste momento é que a ausência ou debilidade do controle de desempenho prejudica seriamente o cenário institucional que favorece a existência e fixação dos cargos de direção, segundo a concepção que temos destes últimos. Quando esse déficit de accountability se dá em estruturas descentralizadas, conduz à formação 
de feudos tecnocráticos e evolui para a fragmentação patológica dos sistemas públicos, que tendem a ficar privados dos elementos de coesão global imprescindíveis. Parte considerável do processo de criação de organismos e empresas públicas em nossas administrações tem sofrido, provavelmente, dessas deficiências. Nesses cenários, as regras e incentivos que estimulam exercício eficaz e responsável da gerência tendem a se sobressair pela ausência do controle de desempenho.

Desde logo, a eficiência de um sistema de controle do desempenho dos dirigentes, baseado em resultados, tem relação não só com a existência de regras formais impostas e de sistemas de informação que os alimentem, mas também com o desenvolvimento de novas capacidades de controle nas tecnocracias organizacionais. A mudança na tipologia predominante dos controles supõe a gestão dos processos de transformação e aprendizagem nas organizações, cuja condução não é fácil. A existência de novas e sólidas tecnocracias, tecnicamente qualificadas e adaptadas à nova filosofia de controle, sendo este exercido com plena eficácia, forma parte do panorama institucional em que a gerência pública frutifica.

\section{Regime de incentivos}

A confluência dos elementos que se acabou de mencionar e descrever configura, em si mesma, um marco que incentiva o exercício responsável da função de direção. Não obstante, o repertório de incentivos ficaria incompleto se não lhe fossem acrescentados mecanismos de reação, que, sendo coerentes com o controle dos resultados, transcendem sua mera avaliação. Concretamente, parece-nos imprescindível a existência de regime de prêmios e sanções associados à avaliação de desempenho do dirigente. Sem este regime, qualquer sistema de controle ficaria previsivelmente privado de eficácia a longo prazo.

Se por um lado, em matéria de controle de desempenho, as especificidades da gestão pública introduziriam notáveis modulações e matizes em relação à prática no setor privado - a própria noção de resultados, e mesmo a de desempenho, poderia ser suscetível a isso -, por outro, em matéria de prêmios e sanções, parece que a proximidade entre os setores privado e público pode ser maior no que diz respeito ao conteúdo de ambos. De fato, assim como ocorre no mundo das empresas, os principais estímulos positivos se relacionam com as políticas e práticas de carreira e compensações, entre outros. Quanto aos estímulos negativos, o mais importante seria, sem dúvida, a vinculação da permanência no cargo a um desempenho positivo ou, pelo menos, aceitável.

As diferenças mais significativas entre os setores privado e público, nesse campo, são referentes aos mecanismos de administração do sistema de incentivos. Nesse ponto, a necessidade de preservar o caráter 
profissional dos dirigentes públicos, em universo organizacional dirigido pela política, requer a introdução de alguns mecanismos de garantia mais consistentes do que no mundo empresarial. Tais mecanismos devem ser destinados a evitar que a pilotagem da administração pública se perca em práticas arbitrárias ou clientelistas ou, simplesmente, que as lealdades políticas ou pessoais se imponham sobre as considerações de competência profissional e de desempenho (Longo, 1999).

Isso não quer dizer que tais garantias devam dar lugar a universo comum de normas que integre os cargos de direção profissionalizados no quadro geral de servidores. Pelo contrário, a criação de regime de incentivos capaz de estimular adequadamente o surgimento e a detecção de vocações para a direção, bem como o exercício dessa direção exige pautas específicas de flexibilidade, similares àquelas que ocorrem nas empresas e superiores às que normalmente caracterizam os regulamentos gerais do emprego público. A clara vinculação entre a continuidade no cargo, a carreira e a retribuição aos resultados formaria parte das regras do jogo, capazes de possibilitar esse marco de prêmios e sanções.

Essa convicção parece ter importância entre os condutores de reformas que, como já mencionados, impulsionaram mudanças no âmbito das democracias avançadas. A criação de estatutos específicos para os dirigentes, destacada como orientação freqüente, responde a essa necessidade de combinar os mecanismos de garantia da profissionalização gerencial com a possibilidade de aplicar regras de gestão de recursos humanos adaptadas aos cargos de direção.

\section{Conjunto de valores de referência}

O quarto e último elemento que configura o marco de responsabilidade do dirigente aponta para a dimensão menos tangível que se identifica com um ethos, o conjunto de valores que norteiam o exercício da função de direção no setor público e são capazes de dotar os dirigentes de identidade axiológica própria, diferente da que caracteriza os demais atores presentes nos sistemas político-administrativos. Dessa identidade derivam orientações, pautas de ação e limites ou restrições, configurando padrão de conduta ou conjunto de "rotinas institucionais" (March; Olsen, 1989, p. 21 et seq.) dos dirigentes públicos, baseadas em lógica do que é apropriado ou não.

O ethos específico dos dirigentes públicos tem como eixo valores de racionalidade econômica, entendida como criação do máximo valor público possível, mediante a utilização eficiente dos recursos consignados, utilizando-nos do termo popularizado por Moore (1995) e já mencionado neste texto. $\mathrm{O}$ dirigente opera no contexto de delegação implícita de caráter otimizador do conjunto de meios à sua disposição. Nesse contexto, 
racionalidade econômica não deve, portanto, ser confundida com orientações economicistas, centradas na mera redução de custos, ou com a aplicação de critérios de rentabilidade que ignorem, na ação pública, as dimensões menos suscetíveis de medida quantitativa ou as externalidades positivas concorrentes em cada caso. Significa, pelo contrário, propósito de maximizar o impacto, estando consciente da utilização de recursos escassos, de modo a avaliar e tornar transparentes os custos de cada ação ou serviço e incluir os custos de oportunidade. Por isso, o dirigente torna-se responsável pelo funcionamento racional do sistema, na parte submetida à sua autoridade formal. O value for money, popularizado pelos reformistas britânicos, expressava de forma eloqüente esse ethos gerencial.

Ainda que a racionalidade econômica não seja patrimônio exclusivo da gerência e incorpore valores que possam ser compartidos com o todo, nenhum dos outros dois grandes atores institucionais - os políticos e os burocratas a serviço da administração - a incorporam como eixo constitutivo de seu ethos específico. É de se dizer, sem aprofundamento nisso agora, que os valores dominantes situar-se-iam, no primeiro caso, em torno da noção de representatividade e, no segundo, incorporariam os modelos deontológicos próprios de cada atividade pública. Os managers são os atores que acrescentam essa orientação valorativa específica aos sistemas político-administrativos. Por isso, a incorporação da eficiência ao modo de pensar e fazer as coisas no serviço público é inseparável do desenvolvimento do sistema de cargos de direção, do qual ela é, ao mesmo tempo, causa e efeito.

Mesmo assim, é precisamente isso que justifica a atribuição do "direito de gerenciar" aos dirigentes. A base que fundamenta a incorporação, pelo desenho institucional, de espaço gerencial razoavelmente protegido da intromissão política e da interferência burocrática é o fato de o dirigente protagonizar essa orientação dominante, de forma exclusiva entre os atores institucionais dos sistemas públicos. Por sua vez, só a manutenção da chamada identidade valorativa - e sua tradução em resultados de gestão coerentes - legitima a manutenção de tal margem de discricionariedade.

Essas considerações vêm sustentar a argumentação de Richards (1994), já mencionada anteriormente, acerca do surgimento do sistema de cargos de direção no setor público, vinculando-o à crise fiscal do Estado de bem-estar e à necessidade de impulsionar melhorias de eficiência. De qualquer forma, parece não haver dúvida de que os cenários de dificuldades financeiras tenham favorecido, em certos casos, as reformas gerenciais. Isso não significa que haja aí relação de causalidade, que poderia ser refutada pela análise de outras experiências. 


\section{Áreas de intervenção para a institucionalização dos cargos de direção no setor público}

Que reformas ou, simplesmente, que linhas de intervenção sobre a realidade são necessárias para alcançar um grau de desenvolvimento do sistema de cargos de direção que permita falar de sua "institucionalização", isto é, de incorporação ao sistema público do marco de responsabilidade que se acabou de descrever, assim como de estágio de consolidação que permita razoável estabilidade? Tentar-se-á, a seguir, dar resposta a essa pergunta, fazendo críticas a diferentes áreas que carecem de intervenção.

\section{A estrutura organizacional}

A estrutura organizacional, ou seja, o conjunto das formas que a organização adota para dividir e coordenar o trabalho (Mintzberg, 1984), é uma das principais áreas afetadas. Há duas variáveis principais do desenho estrutural nas quais a institucionalização do sistema de cargos de direção exige reformas significativas.

A primeira delas está relacionada com o nível em que se situam o poder de decisão e o jogo centralização-descentralização. O habitat estrutural que favorece a fixação e o desenvolvimento da gerência pública exige, como já visto, desenhos descentralizados, se comparados com os padrões estruturais próprios das burocracias públicas tradicionais. Estamos falando de descentralização vertical limitada, em que parte do poder de decisão flui e se desprende do vértice estratégico (direção política) e da tecnoestrutura, fortalecendo a capacidade decisória da parte superior da camada gerencial média (gerentes operacionais). Conforme mencionado anteriormente, a configuração de espaço de discricionariedade de direção exige tanto a delegação estável de poder decisório, quanto a transferência de autonomia de gestão sobre os recursos.

A segunda aponta para a construção de sistemas de planejamento e controle baseados em resultados, capazes de fundamentar controle adequado de desempenho do dirigente, o que implica igualmente mudança significativa da tipologia e administração de controles.

A intervenção sobre a estrutura não é condição suficiente, mas necessária para a institucionalização dos cargos de dirigentes públicos. $\mathrm{O}$ novo marco de responsabilidade baseia-se em desenho estrutural que as burocracias públicas não julgam conveniente, no que diz respeito tanto às burocracias de lógica mecanicista (áreas tradicionais) como às de lógica profissional (prestação de serviços às pessoas). Quando os dirigentes públicos vêem-se obrigados a desempenhar sua tarefa nesses marcos 
estruturais, o que é bastante freqüente, o normal é que se produza todo tipo de "ruídos" organizacionais, que consomem grande quantidade de energia e limitam tanto os resultados de gestão como a consolidação da gerência pública a longo prazo.

\section{As regras formais de gestão de recursos humanos}

O marco jurídico regulador das políticas e práticas de gestão dos recursos humanos $(\mathrm{GRH})$ é, sem dúvida, outra área de intervenção, que tem dois objetivos principais, como se depreende de considerações anteriores:

a) dispor de sistema formal de gestão de pessoal para os cargos de direção, assumindo como princípio fundamental a profissionalização desses cargos. Isso requer a existência de garantias jurídicas capazes de proteger da politização e da arbitrariedade o exercício da gerência pública;

b) incorporar regulamentos que possibilitem a consecução do objetivo anterior, mediante mecanismos adequados para a gestão de dirigentes, o que implica regulamentos específicos, em matéria de recrutamento, nomeação, carreira, remuneração e demissão, mais flexíveis do que as regras aplicadas aos demais servidores públicos.

A intervenção nesse campo deverá enfrentar, de um lado, a tendência freqüente de se preencher, por critérios políticos, um número excessivamente amplo de cargos de direção - desvio que, em outro momento, foi chamado de "colonização" do espaço dos dirigentes (Longo; 1999b, p. 34 et seq.) e, de outro lado, a pretensão de burocratizar os cargos de direção, impondo-lhes padrão homogêneo de regulamentos que os aproximem da burocracia tradicional, concebendo-os como se fossem apenas uma categoria superior dentro do quadro geral de servidores.

Como visto, uma das estratégias adotadas em diversos países tem sido a elaboração e aprovação de estatutos específicos para os dirigentes, o que não quer dizer que não haja outras linhas de reforma capazes de produzir resultados semelhantes. O importante é conseguir que as regras formais que enquadram a gestão dos dirigentes facilitem a identificação de competências de direção, com a flexibilidade e as adaptações necessárias, que facilitem, ainda, sua distribuição nos cargos mais adequados, seu estímulo e motivação permanentes, sua mobilidade e substituição quando necessária e, em definitivo, o conjunto de políticas e práticas de pessoal exigidas por gestão moderna e eficaz de recursos humanos em nível de direção. 


\section{As competências gerenciais}

Pouco serviria, na prática, o que acabamos de expor, sem a existência de dirigentes capacitados para desempenhar o papel que lhes foi reservado. A institucionalização dos cargos de direção requer dirigentes dotados de competências - termo atual no jargão da gestão de recursos humanos. As competências, ou as "características subjacentes a uma pessoa, causalmente relacionadas com uma atuação bem-sucedida em um posto de trabalho" (Boyatzis, 1982), são utilizáveis como padrão ou norma para seleção de pessoal, planejamento de carreiras e mecanismos de promoção, avaliação de desempenho e desenvolvimento pessoal (Hooghiemstra, 1992). Isso converte as competências em eixo central dos sitemas de gestão de pessoas, tal como hoje acontece em número crescente de empresas e organizações de todo tipo.

Em outra ocasião, tentou-se aprofundar a noção de competências e sua aplicabilidade ao desenvolvimento de dirigentes públicos (Longo, 2002). Limitar-se-á aqui a recordar que a noção de competências transcende a de conhecimentos técnicos. A qualificação para a direção depende de conjunto de atributos, entre os quais devem incluir-se motivos, traços de caráter, conceito de si mesmo, atitudes ou valores, habilidades e capacidades cognitivas ou de conduta. A combinação dessas qualidades em perfis de competência de direção capazes de representar desempenho de sucesso obriga a adoção de processos que possuam forte carga situacional. Por isso, a análise do contexto é parte muito importante desses processos. A definição de perfis de competências adaptados à realidade é um primeiro passo imprescindível para empreender práticas de gestão destinadas a fortalecer a capacidade de direção nas organizações públicas.

A formação de massa crítica de dirigentes competentes exigirá, a implementação de robustos programas de desenvolvimento de dirigentes, conjugando diferentes tipos de política de recursos humanos que englobem recrutamento, remuneração, carreira, avaliação e desenvolvimento. Sem dúvida, o grau de facilidade e/ou dificuldade desse processo de implementação dependerá dos ganhos alcançados nas reformas referidas anteriormente. A expansão das competências de direção, por sua vez, pode ser vista como fator dinamizador das mudanças estruturais e normativas mencionadas, como se insistirá mais adiante.

\section{A cultura política e as culturas organizacionais}

Sem dúvida, a institucionalização dos cargos de direção nos sistemas públicos carrega importantes conotações de mudança cultural. A cultura ainda dominante nesses sistemas - o conjunto de regras informais, os 
modelos mentais, a percepção do que é apropriado em cada caso e as normas de conduta resultantes - está longe de ter interiorizado o management, a gerência pública. Esta se encaixa melhor em nova ordem cultural, em grande medida, uma "contracultura", em relação à tradição burocrática ainda hegemônica na maior parte da estrutura organizacional do setor público.

A mudança cultural necessária para o desenvolvimento e a fixação do sistema de cargos de direção deve produzir-se, em diferentes escalas, sobretudo em duas frentes: a da cultura política global da sociedade e a da cultura interna das diferentes organizações públicas.

A primeira dessas frentes implica desafio diário de nossa cultura política, em particular no que diz respeito às relações entre política e administração. Torna-se imprescindível a superação daquilo que, em outro texto, se chamou de "metafísica da confiança" (Longo, 1999b, p. 36), legitimadora de visões colonizadoras da gerência pública pelas classes políticas. $\mathrm{Na}$ base dessa nova cultura de autolimitação da política, há, por um lado, nova concepção sobre a forma de dirigir as instituições e, por outro, convicção de que a existência de administração profissionalizada - da qual os dirigentes são parte inseparável - constitui senha de identidade das democracias avançadas. Já são muitas as evidências de que esses modelos autolimitadores, respeitadores do espaço reservado à gerência pública, não "despolitizam” a administração. Pelo contrário, geram habitualmente maior controle das organizações públicas pela política.

A segunda frente indica o repertório de assunções tácitas compartilhadas que configurariam o substrato cultural profundo das organizações públicas (Schein, 1999). O que se observa aqui, na maioria dos casos, são estruturas culturais que representam, simbolizam e legitimam diferentes modalidades de coexistência e interação entre os dois atores da tradição weberiana: políticos e burocratas; ou as diversas manifestações concretas do paradigma burocrático da administração pública, ao qual são alheios a figura e o papel do manager público. A consolidação dos cargos de direção públicos basear-se-á, necessariamente, na superação desses elementos culturais, por meio de longos e lentos processos que, ao mesmo tempo, estimularão e serão estimulados por avanços nas outras áreas de intervenção mencionadas.

\section{Desafios e dificuldades}

Por onde começar? Qual é o itinerário, o mapa, quais os companheiros de viagem e os veículos que conduzem a um cenário de institucionalização dos cargos de direção no setor público? Como os esforços de reforma da administração podem servir para fixar e consolidar 
modelos de gerência profissionalizada nos sistemas públicos? De que variáveis isso depende? Após falar-se fundamentalmente de conteúdos, dedicar-se-á esta parte do texto à reflexão sobre essas questões básicas de um processo de mudança.

Uma primeira questão pode relacionar-se às áreas de intervenção indicadas anteriormente: em que ordem e com que prioridades desenhar uma estratégia de mudança? Para viabilizar as demais reformas, o marco legal deve ser alterado logo no início? É necessário enfrentar uma ofensiva cultural para criar o gerador das mudanças? As reformas estruturais são prévias? Há necessidade de se criarem, primeiro, as capacidades de direção?

Não parece existir resposta genérica a essas perguntas. Não existe um único caminho possível. Ademais, as estratégias de mudança mais viáveis serão as que se basearem no conhecimento mais próximo possível da realidade. As circunstâncias confluentes em cada contexto institucional podem impor diferenças de enfoque significativas. Diante disso, parece evidente que a intervenção sobre as quatro áreas mencionadas anteriormente constituiria a opção mais contundente, já que cada uma das linhas de intervenção citadas retroalimenta as demais áreas, sendo, ao mesmo tempo, estimulada por elas. O problema é que tais enfoques sistêmicos só estão ao alcance de iniciativas globais de reforma que sejam dotadas, por sua vez, de clara visão e vontade de mudança e de poder político consistente. Nem sempre esse é o caso.

Sem pretensão de generalizar, pode-se dizer que o desenvolvimento de dirigentes, crescentemente assumido como prioridade em nosso ambiente próximo, tem desempenhado importante papel dinamizador. As organizações públicas que, na falta de capacidade para impulsionarem outras reformas, investem em criar e desenvolver dirigentes, utilizando como referência modelos de gerência pública do tipo descrito, interiorizam estímulos para a mudança que podem impulsioná-la em outros campos. Voltar-se-á a essa idéia posteriormente.

Alguns fatores parecem particularmente relevantes para a produção de processos de institucionalização dos cargos de direção no setor público. Abordar-se-ão esses fatores a seguir, argumentando-se sobre a sua importância e indicando-se, ao mesmo tempo, os obstáculos mais significativos.

\section{Liderar com firmeza mudanças complexas}

Não é preciso insistir na necessidade de liderança dotada de visão e capaz de transmiti-la e de estimular adesões. Toda mudança complexa requer condução comprometida e coerente. Sem aprofundar a descrição do papel e das características dessa liderança, enfatizar-se-á a importância 
crucial da capacidade de se criar sensação de necessidade e urgência (Kotter, 1996, p. 35 et seq.), sem a qual seria impossível que as organizações públicas chegassem a questionar, abandonar e substituir paradigmas tradicionais, muito antigos e profundamente arraigados. Crê-se que seja por isso que o impulso à gerência pública se apóie preferencialmente, como visto, em cenários críticos, como são, entre outros, os ajustes orçamentários, favoráveis ao questionamento das rotinas e permeáveis a idéias e práticas transformadoras.

Não está escrito onde encontrar uma liderança assim. Certamente, em nosso contexto institucional, os temas abordados não são habitualmente incluídos nas prioridades da agenda política dos governos. Contudo, poucos negariam o desenvolvimento da gerência pública entre nós, apesar do déficit de institucionalização constatável. O impulso a processos de reformas gerenciais pode ser constatado em instâncias e circunstâncias diversas: há exemplos produzidos em escalas muito diferentes, desde a global e sistêmica até a setorial e reduzida; intervenções de caráter eventual e outras de caráter permanente; desenvolvimentos centralizados e contundentes, "de cima para baixo" ou, pelo contrário, periféricos, graduais e participativos.

Uma pergunta interessante a ser feita é: por que os dirigentes da Catalunha alcançaram grau relativamente alto de permanência e expansão no mundo local? Diversos fatores contribuíram para isso, como, por exemplo: a) a existência de tradições burocráticas menos sólidas; b) o choque dessas tradições com demanda social muito próxima; c) a forte característica de prestação de serviços presente na ação pública local e suas conseqüentes necessidades de "empresarialidade"; d) a crise financeira produzida por fortíssima expansão da oferta de serviços; e) a própria fragmentação municipal e sua localização na periferia do sistema político-administrativo; e f) sem dúvida, o surgimento de lideranças políticas que interiorizaram visões transformadoras acerca de como dirigir as organizações locais. Tudo isso não evitou a existência de notáveis contradições e déficits, já comentados com alguma profundidade em outros trabalhos (Longo, 1998, 1999b).

Uma das necessidades que a institucionalização da gerência pública busca suprir, e provavelmente uma das maiores dificuldades, é a de manter visões de longo prazo, capazes de dar continuidade a processos de mudança que, por sua própria natureza, são de longo alcance. É recorrente na gestão pública o tema das restrições que o ciclo político, por favorecer uma lógica predominantemente de curto prazo, impõe à consolidação das inovações. Somente lideranças dotadas da persistência e tenacidade necessárias são capazes de vencer esse tipo de obstáculos. 


\section{Impulsionar o desenvolvimento}

de dirigentes

O desenvolvimento de dirigentes públicos é, sem dúvida, um dos eixos básicos desses processos. A dimensão dual do desenvolvimento - transmissão de conhecimentos e de habilidades e modificação de atitudes e valores - relaciona-o diretamente com duas das áreas de intervenção, referidas anteriormente: por um lado, incrementa as competências de direção disponíveis; por outro, contribui de maneira decisiva para a mudança cultural. O desenvolvimento de dirigentes públicos alcançou, nas últimas décadas, enorme expansão em todo o mundo. Como apontado há pouco, a presença nas organizações públicas de número crescente de dirigentes convencidos de seu papel e dotados das competências para exercê-lo é, por si mesma, fator dinamizador das mudanças referidas. Sua lógica inclinação a exigir espaço próprio e a incorporação a suas organizações de valores e modelos intelectuais diferentes, que contrastam com a tradição burocrática, são elementos que dispõem de indiscutível potencial transformador. $\mathrm{O}$ investimento em capacitação tem sido, em muitos casos, um começo de mudanças importantes nas estruturas e maneiras de fazer das organizações públicas, o que não é um mau começo.

Seria erro pensar que o desenvolvimento de dirigentes, por seu caráter soft, freqüentemente mais acessível e fácil de administrar do que, por exemplo, as reformas estruturais e legais, constitui, em si mesmo, a solução para institucionalizar o sistema de cargos de direção no setor público. Quando a capacitação adquire esse caráter totêmico, pode encobrir o panorama e prover imagem enganosa e parcial do programa de reformas necessárias. Por outro lado, pode levar à frustração de muitas pessoas: àquelas que, após serem capacitadas como managers e tentarem, sem êxito, encontrar espaço e apoio para se desempenharem como tal, acabam comprovando que, por trás da formação, não existia um propósito deliberado de reformar com profundidade a administração e consolidar a gerência pública. Isso não quer dizer que essas soluções "arruínam" as reformas e produzem aprendizagens organizacionais de características contrárias ao que se está propondo.

\section{Desenvolver identidade coletiva}

A figura do dirigente é relativamente nova nos sistemas públicos, como indicado na primeira parte deste trabalho. Sua irrupção altera um status quo protagonizado pelos dois atores clássicos do paradigma weberiano: políticos e burocratas e faz com que a figura do manager - $\mathrm{o}$ que já foi comentado anteriormente - traga consigo certa carga contracultural que a converte em algo emergente, pouco consolidado, 
dotado de contornos ambíguos e, com certa freqüência, sob a resistência de outros atores institucionais que enfrentam o seu surgimento com temor ou preocupação. Definitivamente, quando, no entorno da administração, fala-se em cargos públicos de direção, é possível, entretanto, que se esteja falando sobre coisas consideravelmente diferentes, que respondem a percepções, valores ou interesses distintos.

Diante de tudo isso, a institucionalização da gerência pública profissionalizada exigirá avanços no desenvolvimento de identidade coletiva reconhecível. Para isso, parece necessária a existência de massa crítica suficiente de pessoas que se percebam como dirigentes públicos, construindo essa percepção a partir de modelo comum de funções de direção e de acordo com os traços básicos descritos, bem como a partir de conjunto de competências profissionais distintivas, coerentes com aquele modelo.

Algumas iniciativas que contribuiriam para o desenvolvimento e reconhecimento dessa identidade coletiva são: a criação e o desenvolvimento de diversos tipos de vínculo, a frequiência dos intercâmbios, a coincidência em programas de capacitação gerencial, a participação em redes de gerentes públicos de diferentes naturezas e âmbitos, a implementação de iniciativas de associação, de mecanismos específicos de apoio profissional e de fóruns de debate. É de se acreditar que tanto a administração quanto as instituições acadêmicas mais vinculadas à capacitação em gestão pública estão sendo solicitadas a dar seu apoio e a colaborar. O congresso no qual se apresentam essas reflexões seria exemplo disso.

\section{Mudar as normas}

Antes, já se disse que o marco jurídico é uma área em que as reformas são inevitáveis, se o desejo é institucionalizar os cargos públicos de direção. Nem a legislação vigente sobre a função pública, nem as leis sobre as organizações, nem o resto das normas aplicáveis respaldam com eficácia um modelo de gerência pública profissionalizada como aquele em que se está refletindo, o que contribui para um claro déficit de institucionalização. Diversas vozes (Jiménez Asensio, 1995, 1998. Losada, 1995. Férez, 1995) já falaram da necessidade de marco estatutário específico, capaz de garantir, com a flexibilidade necessária, o acesso de perfis de dirigentes profissionalizados e as condições adequadas para o exercício da função, protegendo-a tanto de desvio burocrático-funcional quanto da aproximação de administração mais politizada. Compartilhamos plenamente dessas opiniões, mas não acreditamos que a mudança legal seja, em muitos casos, a melhor forma de iniciar as reformas. A história dos sistemas político-administrativos e, em particular, a nossa estão cobertas de 
exemplos de mudanças normativas que não induziram reais transformações de base.

Em todo caso, o desenvolvimento da função de dirigente não pode nem deve esperar as reformas jurídicas. Em primeiro lugar, porque as necessidades das organizações públicas as precedem. Em segundo, porque as melhores reformas legais são aquelas que consolidam e institucionalizam as mudanças efetivamente produzidas, mais do que as que definem, $a$ priori, seus conteúdos. Por último, porque o principal agente propulsor do desenvolvimento da função de dirigente público não é o legislador, mas, sim, os governos. Somente quando as novas normas forem acompanhadas de claras estratégias governamentais de mudança, servirão realmente para mudar as coisas.

\section{Iniciar o debate das idéias}

Tem-se feito reiterada alusão à dimensão ideológica ou cultural das mudanças necessárias para institucionalizar os cargos públicos de direção. Fugindo de repetições, insiste-se nisso nesta parte final do trabalho. A expansão da gerência pública responde à necessidade de adaptar as organizações e os sistemas aos principais desafios traçados pelas sociedades contemporâneas. A existência de bons dirigentes, em número suficiente, e a consolidação de modelo que os produza, proteja e estimule o exercício de sua função e equilibre adequadamente sua importância com a dos demais atores da divisão político-administrativa são variáveis cruciais das reformas institucionais necessárias.

O debate da gerência pública não está à margem dos grandes debates contemporâneos. De fato, relaciona-se diretamente com a qualidade das respostas públicas aos grandes temas de nosso tempo. O sistema de cargos públicos de direção, tal como se tentou aproximar dele, não oferece repertório tecnocrático de soluções aos problemas sociais. Pelo contrário, insere-se no cenário complexo em que os governos e as organizações públicas tentam produzir liderança social capaz de enfrentar a mudança adaptativa (Heifetz, 1997). É um cenário em que as incertezas predominam sobre as certezas, os conflitos de interesses e valores sobre os consensos e a necessidade de aprendizagem social sobre a legitimidade das soluções técnicas, as quais pretendem ser imparciais. A contribuição da gerência pública não se baseia em tentativa de simplificar essa complexidade com algumas receitas instrumentais, mas, sim, de melhorar a capacidade institucional dos governos para enfrentá-la. A institucionalização dos cargos de direção não é opção separada da política. Longe de substituí-la, vem facilitá-la, valorizá-la e potencializa o seu papel de comando nas intervenções públicas, muito além da mera atribuição formal. 
Levar essas idéias ao debate político e social será imprescindível para a fixação e consolidação dos cargos públicos de direção. Por mais trabalhoso que seja conseguir que os problemas da administração cheguem à opinião pública, os temas dos quais se falou não afetam simplesmente os funcionários que se acham diretamente interessados, ou os acadêmicos que tenham feito deles um campo de especialidade. A institucionalização da gerência pública é tema central para a governabilidade das sociedades democráticas contemporâneas e, por isso, cabe à sociedade em seu conjunto.

\section{Nota}

1 Para a redação deste trabalho, o autor se baseia em lições e conversas de trabalho com seu colega do IDGP da ESADE, hoje no Banco Interamericano de Desenvolvimento, professor Koldo Echebarria, cujas idéias adapta e desenvolve aqui, sem que isso implique transferência alguma de autoria sobre o trabalho, cuja redação é da exclusiva responsabilidade do autor.

\section{Referências bibliográficas}

BarZelay, M. Atravesando la burocracia: una nueva perspectiva de la administración pública. México D.F.: Fondo de Cultura Económica, 1998.

. The new public management: improving research and policy dialogue.

Berkeley-Los Angeles: University of California Press, 2001.

Boston, J. et al. Public management: the New Zealand model. Oxford University Press, 1997.

Bourgault, J.; Savole, D. J. Managing at the Top. In: Peters y Savoie (Ed.) Governance in the twenty first century: revitalizing the public service. Montreal/Kingston: McGill-Queen's University Press, 2000.

BoyATZIS, R. E. The competent manager: a model for effective performance. New York: John Wiley and Sons, 1982.

Burnham, J. Human resources flexibilities in France. In: Farnham, D.; Horton, S. (Ed.) Human resources flexibilities in the public services. Macmillan Business, 2000.

CABrero, E. Evolución y cambio en la administración pública: del administrador al gerente público. México: INAP, 1991. 
Clarke, J.; Newman, J. The managerial State: power, politics and ideology in the remaking of social welfare. London: Sage Publications, 1997.

DALZIEL, M. Building competitive advantage trough people. In: People and Competencies. London: Kogan Page, 1996.

DoLAn, J. Influencing policy at the top of the federal bureaucracy: a comparison of career and political senior executives. Public Administration Review. v. 60, n. 6, p. 573-581, nov./ dec. 2000.

Dunleavy, P.; Hood, C. From old public administration to new public management, Public Money and Management, p. 9-16, july/sept. 1994.

ECHEBARRIA, K. La administración pública en la era del management: reflexiones sobre una década de modernización administrativa. Tesis doctoral. 1993. Universidad de Deusto.

Férez, M. El sistema de mérito en el empleo público: "principales singularidades y analogías respecto del empleo en el sector privado. Documentación Administrativa, Madrid, n. 241-242, 1995.

HeIFETz, R. A. Liderazgo sin respuestas fáciles: propuestas para un nuevo diálogo social en tiempos difíciles. Barcelona/Paidós: Estado y Sociedad, 1997.

Hood, C. Relations between ministers and public servants: public service bargains old and new. In: Peters y SAVOIE (Ed.). Governance in the twenty first century: revitalizing the public service. Montreal/Kingston: McGill-Queen's University Press, 2000.

Hooghiemstra, T. Gestión integrada de recursos humanos. In: Mitrani, A. et al (Ed.). Las competencias, clave para una gestión integrada de los recursos humanos. Bilbao: Deusto, 1992.

JiMÉNEZ AsENSIO, Rafael. Regímenes jurídicos de función directiva en las administraciones públicas españolas. Documentación Administrativa. Madrid, n. 241-242, 1995.

Altos cargos y directivos públicos: un estudio sobre las relaciones entre política y administración en España. 2. ed. ampliada y adaptada. Oñate: Instituto Vasco de Administración Pública, 1998.

Kotter, J. P. Leading change. Boston: Harvard Business School Press, 1996.

LAEgreID, P. Top civil servants under contract. Public Administration, v. 78, n. 4, 2000.

Longo, F. Burocracia y postburocracia en el diseño organizativo. In: LosADA, C. (Ed.) ¿De burócratas a gerentes? Las ciencias de la gestión aplicadas a la administración del Estado. Washington DC: Banco Interamericano de Desarrollo, 1999.

. Política y gerencia pública en los gobiernos locales. In: Gobierno Local y Modelo Gerencial. Barcelona: Fundación Pi i Sunyer, 1999.

. Sistema político y participación ciudadana en el gobierno local español.

In: Estudios sobre los Gobiernos Locales. Granada: Centro de Estudios Municipales y de Cooperación Internacional, 1998.

.El desarrollo de competencias directivas en los sistemas públicos: una prioridad del fortalecimiento institucional. Ponencia para el VII Congreso del CLAD. Pendiente de publicación, 2002.

LosADA, C. La función de dirigir en la administración pública. In: Losada, C. (Ed.) ¿De burócratas a gerentes? Las ciencias de la gestión aplicadas a la administración del Estado. Washington DC: Banco Interamericano de Desarrollo, 1999.

. Las especificidades de la gestión pública: implicaciones en la función directiva pública. Documentación Administrativa. Madrid: n. 241-242, 1995.

MARCH, J. G.; OlsEN, J. P. Rediscovering institutions: the organizational basis of politics. New York: Free Press, 1989. 
Martínez Bargueño, M. La reforma de la relación de empleo público en Italia. Gestión y Análisis de Políticas Públicas. Madrid, n. 2, 1995.

MendozA, X. Management público e indicadores de gestión: una perspectiva organizativa. Ekonomiaz, Vitória, n. 26, p. 45 et seq., 1993.

Metcalfe, L. Conviction politics and dynamic conservatism: Mrs. Thatchers managerial revolution. International Political Science Review, v. 14, 1993.

MintzBerg, H. La estructuración de las organizaciones. Barcelona: Ariel, 1984.

Moore, M. H. Creating public value: strategic management in government. Cambridge/ Massachusets: Harvard University Press. 1995.

MurRay, R. Human resources mangement in Swedish Central Government. In: FARnHAM, D.; Horton, S. (Ed.). Human resources flexibilities in the public services. Macmillan Business, 2000.

OCDE. The state of the higher civil service after reform: Britain, Canada and the United States. Paris: OECD, 1999.

OECD, 1999. . Issues and developments in public management: country reports. Paris:

PolLitT, C. El gerencialismo y los servicios públicos: la experiencia anglo-norteamericana. Madrid: Instituto de Estudios Fiscales, 1993.

Pollitt, C.; BoucKaert, G. Public management reform: a comparative analysis. Oxford University Press, 2000.

Pollitt, C.; Birchall, J.; Putman, K. Decentralising public service management: the British experience. Basingstoke: Macmillan, 1998.

Richards, S. El paradigma del cliente en la gestión pública. Gestión y Análisis de Políticas Públicas, Madrid, n.1, 1994.

RIDLEY, F. F. Public service flexibility in comparative perspective. In: FARNHAM, D.; HorTon, S. (Ed.). Human resources flexibilities in the public services. Macmillan Business, 2000.

SÁnCHEZ Morón, M. Sobre la reforma administrativa italiana del período de transición, con especial referencia a la organización administrativa y al empleo público. Revista de Administración Pública, n. 134, mayo/ago. 1994.

Schein, E. The corporate culture survival guide. San Francisco: Jossey-Bass Publishers, 1999.

SCHWARTZ, H. M. Public choice theory and public choices: bureaucrats and state reorganization in Australia, Denmark, New Zealand and Sweden in the 1980s. Administration and Society, n. 1, mayo, 1994.

STRAND, T. The public manager: bureaucrats or contingent actors. In: KoOIMAN, Jan; EliASSEN, Kjell. Managing Public Organisations. Sage Publications, 1987.

VAn der Krogt, T.; BeErsen, E.; Kemper, A. The Netherlands: towards personnel flexibilities. In: Farnham, D.; Horton, S. (Ed.). Human resources flexibilities in the public services. Macmillan Business, 2000.

World BANK. Administrative and civil service reform. Washington DC: The World Bank Group, 2000 . 


\section{A consolidação institucional do cargo de dirigente público}

\section{Francisco Longo}

O trabalho pretende desenvolver uma reflexão sobre a profissionalização dos cargos de direção na administração pública e sua evolução ao longo das últimas décadas nos países desenvolvidos, tendo como eixo condutor a institucionalização dos cargos de dirigentes públicos nos sistemas político-administrativos contemporâneos. Inicia-se definindo a expansão e o desenvolvimento do gerenciamento nos sistemas públicos, descrevendo, de forma breve e comparada, sua evolução mais recente em alguns países da OCDE. Em seguida, são apontados os traços básicos de um modelo de exercício das funções de direção na administração pública. A seguir, trata-se do tema central mencionado. Primeiramente, o texto define os elementos que configuram um marco institucional para as funções de direção no setor público. Depois, aborda o conteúdo, o alcance e o âmbito das reformas necessárias para a construção desse marco. Por último, analisa as variáveis que podem influenciar a elaboração das reformas, expondo os principais desafios e dificuldades traçados pelos empenhos de reforma.

\section{La consolidación institucional del cargo de dirigente público}

\section{Francisco Longo}

El trabajo pretende desarrollar una reflexión sobre la profesionalización de los cargos de dirección en la administración pública y su evolución a lo largo de las últimas décadas en los países desarrollados, teniendo como eje conductor la institucionalización de los cargos de dirigentes públicos en los sistemas político-administrativos contemporáneos. Comienza definiendo la expansión y el desarrollo de la administración en los sistemas públicos, describiendo, de forma breve y comparada, su evolución más reciente en algunos países de la OCDE. A continuación, son colocados los trazos básicos de un modelo de ejercicio de las funciones de dirección en la administración pública. A partir de ahí, se aborda el tema central mencionado. Primeramente, el texto define los elementos que configuran un marco institucional para las funciones de dirección en el sector público. Después, aborda el contenido, el alcance y el ámbito de las reformas necesarias para la construcción de ese marco. Por último, analiza las variables que pueden influir sobre la elaboración de las reformas, exponiendo los principales desafíos y dificultades trazados por los empeños de reforma.

\section{Institutional consolidation of the public manager post}

\section{Francisco Longo}

The text intends to foster a reflection on the professionalization of managerial posts in public administration and their evolution in developed countries over recent decades, using the institutionalization of executive posts in contemporary political-administrative systems as a guiding thread. Initially, the text defines the expansion and development of management in public systems, briefly and comparatively describing its most recent evolution in some OECD countries. Next, the basic traits of a model of managerial posts in public administration are pointed out. Based on this groundwork, the above-mentioned core topic is addressed. First, the text defines the elements that characterize an institutional framework for managerial posts in the public sector. Next, it addresses the contents, reach and scope of necessary reforms for building these basic elements. Finally, it analyzes variables that can influence the definition of these reforms, highlighting the main challenges and difficulties faced in reform efforts.
Revista do

Serviço

Público

Ano 54

Número 2

Abr-Jun 2003

\section{Francisco}

Longo é

licenciado

em Direito

pela

Universidade

de Barcelona,

professor e

diretor do

Instituto de

Dirección y

Gestión Pública

da ESADE em

Barcelona,

Espanha.

Contato:

longo@esade.edu 
